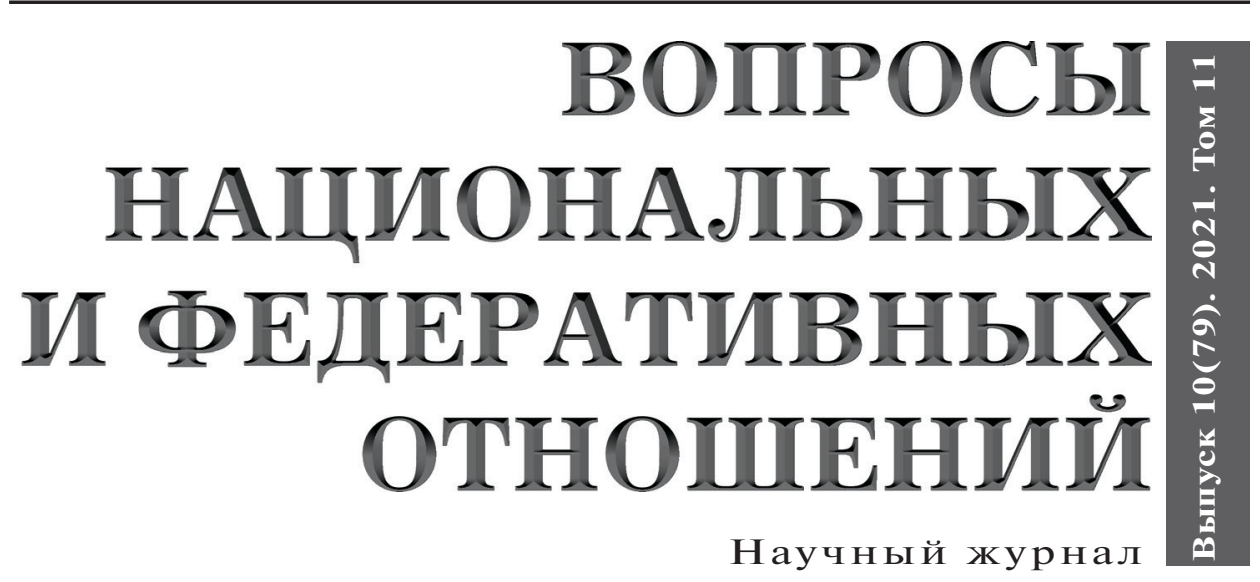

Журнал «Вопросы национальных и федеративных отношений» включен в перечень рецензируемых научных изданий ВАК, в которых должны быть опубликованы основные научные результаты на соискание ученой степени кандидата наук, на соискание ученой степени доктора наук по политическим и историческим наукам 


\section{Научный журнал}

Вячеслав Александрович МИХАЙЛОВ

Рамазан Гаджимурадович АБДУЛАТИПОВ

Любовь Федоровна БОЛТЕНКОВА

Владимир Иванович ВАСИЛЕНКО

Владимир Александрович ВОЛОХ

Вадим Витальевич

ГАЙДУК

Владимир Юрьевич ЗОРИН

Раушан Мусахановна КАНАПЬЯНОВА

\section{В. Микаэль}

КАССАЕ НЫГУСИЕ

Геннадий Яковлевич КОЗЛОВ

Игорь Георгиевич КОСИкОВ

Николай Павлович МЕДВЕДЕВ

Марина Николаевна МОСЕЙКИНА

Александр Данилович НАЗАРОВ

Дарья Вячеславовна ПЕРКОВА

Александр Васильевич ПОНЕДЕЛКОВ

Дмитрий Егорович СЛИЗОВСКИЙ

Шукран Саидовна СУЛЕЙМАНОВА

Жибек Сапарбековна СЫЗДЫКОВА
Председатель Совета, д.и.н., профессор, зав. кафедрой национальных и федеративных отношений РАНХ и ГС при Президенте РФ

\section{Редакционный Совет}

д.ф.н., постоянный представитель Российской Федерации при Организации Исламского сотрудничества

д.ю.н., профессор РАНХ и ГС при Президенте РФ

д.п.н., профессор Российской академии народного хозяйства и государственной службы при Президенте РФ

д.П.н., профессор Государственного университета управления

д.п.н., профессор Башкирского государственного университета

д.п.н., руководитель Центра по научному взаимодействию с общественными организациями, СМИ и органами государственной власти ИЭА РАН

д.п.н., профессор кафедры международного культурного сотрудничества МГИК

д.и.н., профессор кафедры теории и истории международных отношений Российского университета дружбы народов

д.и.н., профессор Рязанского государственного университета им. С.А. Есенина

д.и.н., главный научный сотрудник Института этнологии и антропологии РАН

д.п.н., профессор Российского университета дружбы народов

д.и.н. профессор, заведующая кафедрой истории России Российского университета дружбы народов

д.и.н., профессор, зам. руководителя кафедры по научной работе Московского авиационного института

к.П.н., ответственный редактор

д.п.н., профессор, заведующий кафедрой политологии и этнополитики Южно-Российского института управления - филиал РАНХ и ГС при Президенте РФ

д.и.н., профессор кафедры истории России Российского университета дружбы народов

д.п.н., профессор Российской академии народного хозяйства и государственной службы при Президенте РФ

д.и.н., профессор, заведующая кафедрой стран Центральной Азии и Кавказа Института стран Азии и Африки Московского государственного университета имени М. В. Ломоносова, заместитель главного редактора журнала

Редакционная коллегия

Главный редактор - СУЛЕЙМАНОВА Ш.С., д.П.Н., профессор РАНХиГС

Члены ред. коллегии:

Волох В.А. (зам. главного редактора),

Сыздыкова Ж.С. (зам. главного редактора),

Перкова Д.В. (ответственный редактор),

Болтенкова Л.Ф., Дробижева Л.А., Слизовский Д.Е.

\author{
УЧРЕЖДЕН \\ ООО «Издательство \\ «Наука сегодня»
}

\section{ЖУРНАЛ ВКЛЮЧЕН \\ В ПЕРЕЧЕНЬ ВАК РФ}

Журнал зарегистрирован Федеральной службой по надзору в сфере массовых коммуникаций,

связи и охраны культурного наследия

Регистрационный номер

ПИ № ФС77-47487

от 25 ноября 2011 г.

Журнал издается ежемесячно

Журнал включен в базу РИНЦ

(Российский индекс научного цитирования)

Включен в каталог

Ulrich's Periodicals Directory

Пятилетний импакт-фактор журнала: 1,006

Адрес редакции:

115598 , г. Москва, ул. Загорьевская,

д. 10, корп. 4, цокольный этаж, помещение I, комната 7-1, офис 4

Тел.: (910) 463-53-42

www.etnopolitolog.ru

E-mail: etnopolitolog@yandex.ru

Мнение авторов может не совпадать с мнением редакции

При перепечатке ссылка на журнал обязательна.

Научные статьи, публикуемые в журнале подлежат обязательному рецензированию.

Ответственный редактор Перкова Д.В.

Компьютерная верстка Анциферова А.С.

Подписано в печать 27.10.2021.

Формат 60×84/8. Объем 24,3. Печать офсетная. Тираж - 1000 эКз. (1-й завод - 500 экз.) Заказ № 000 .

Отпечатано в типографии OОO «Белый ветер»

115054, г. Москва, ул. Щипок, 28

Тел.: (495) 651-84-56 
ISSN 2226-8596 (print)

12 выпусков в год и

2 выпуска в год переводной (англ.) версии

Языки: русский, английский

http://etnopolitolog

Входит в перечень рецензируемых научных изданий ВАК РФ

Включен в каталог периодических изданий Ульрих (Ulrich's Periodicals Directory: http://www.ulrichsweb.com) Материалы журнала размещаются на платформе РИНЦ Российской научной электронной библиотеки, Electronic Journals

Library Cyberleninka

Подписной индекс издания в каталоге агентства Роспечать 70114

\section{Цели и тематика}

Журнал ВОПРОСЫ НАЦИОНАЛЬНЫХ И ФЕДЕРАТИВНЫХ ОТНОШЕНИЙ - периодическое международное рецензируемое на ᄀучное издание в области политических исследований. Журнал является международным как по составу редакционного совета и редколлегии, так и по авторам и тематике публикаций.

Научный журнал издается с 2011 года в издательстве «Наука сегодня». С 2018 года издается переводная (англ.) версия журнала. С момента своего создания, журнал ориентировался на высокие научные и этические стандарта и сегодня является одним из ведущих политологических журналов России.

Цель журнала - способствовать научному обмену и сотрудничеству между российскими и зарубежными политологами

Журнал предназначен для публикации результатов фундаментальных и прикладных научных исследований. Тематическая направленность журнала отражается в следующих постоянных рубриках: «Отечественная история, этнология и этнография», «История международных отношений и мировой политики», «История и философия политики», «Политические институты, процессы и технологии», «Политическая культура, этнополитика и идеологии», «Политические проблемы международных отношений и глобализации».

Формат публикаций: научные статьи, обзорные научные материалы, материалы круглых столов, научные рецензии, научные сообщения, посвященные исследовательским проблемам в сфере политики и политологии.

В своей деятельности редакционный совет и редколлегия журнала руководствуется принципами, определяемыми ВАК России для научных журналов, в том числе: наличие института рецензирования для экспертной оценки качества научных статей; информационная открытость издания; наличие и соблюдение правил и этических стандартов представления рукописей авторами.

Целевой аудиторией журнала являются российские и зарубежные специалисты-политологи, а также аспиранты и магистры, обучающиеся по направлениям политология, государственное и муниципальное управление и международные отношения.

Журнал строго придерживается международных стандартов публикационной этики, обозначенных в документе СОРЕ (Committee on Publication Ethics) http://publicationethics.org

Полные сведения о журнале и его редакционной политике, требования о подготовке и публикации статей, архив (выпуски с 2011 года) и дополнительная информация размещена на сайте: http://etnopolitolog.ru

Электронный адрес: etnopolitolog@yandex.ru

ISSN 2226-8596 (print)

12 issues a year plus 2 issues a year of the translated (eng.) version Languages: Russian and English http://etnopolitolog

Included in the list of peer-reviewed scientific publications of the Higher Attestation Commission of the Russian Federation Included in the Ulrich's Periodicals Directory Materials of the journal are placed on the RSCI platform of the Russian scientific electronic library - Electronic Journals Library Cyberleninka Subscription index of the journal in the Rospechat Agency catalogue is: 70114

\section{Objectives and themes}

Academic journal "Issues of National and Federative Relations" is an international peer-reviewed scientific periodical in the field of political studies. The journal has an international character because of the composition of its Editorial Board, its editors, its contributing authors and topics of its publications.

The scientific journal is published since 2011 at the "Publishing House "Science Today". Translated (eng.) version of the journal is published since 2018. Since its inception, the journal was guided by high scientific and ethical standards and today it is one of the leading political science journals in Russia.

The purpose of the journal is to promote scientific exchange and cooperation between Russian and foreign political scientists.

The journal is intended for the publication of the results of fundamental and applied scientific research. Thematic focus of the journal is reflected in the following permanent headings: "Domestic history, ethnology and ethnography", "History of international relations and world politics", "History and philosophy of politics", "Political institutions, processes and technologies", "Political culture, ethnopolitics and ideologies", "Political problems of international relations and globalization."

Format of publications: scientific articles, reviews, scientific materials, materials of round tables, scientific reviews, scientific reports devoted to research problems in the field of politics and political science.

The Editorial Board and the editors of the journal in their activities are guided by the principles defined by VAK of Russia for scientific journals, including: presence of the institute of peer review for the expert quality assessment of scientific articles; information openness of the publications; availability and compliance with the rules and ethical standards for the submission of manuscripts by the authors.

The target audience of the journal is Russian and foreign specialists-political scientists, as well as graduate students and masters in the fields of political science, state and municipal management and international relations.

The journal strictly adheres to the international publishing standards and publication ethics identified in the COPE (COmmittee on Publication Ethics) document. http://publicationethics.org.

Full details of the journal and its editorial policy, requirements to the preparation and publication of articles, archive (issues since 2011) and additional information are available on the website: http://etnopolitolog.ru

E-mail address: etnopolitolog@yandex.ru 
ОТЕЧЕСТВЕННАЯ ИСТОРИЯ, ЭТНОЛОГИЯ И ЭТНОГРАФИЯ

Раимов Р.И., Сыздыкова Ж.С. Джадидизм и басмачество:

тенденции и противоречия

Шавлаева Т.М., Дахо А.А., Тесаев 3.А., Садулаев Э.С. К вопросу изучения

Ачхоевско-Бамутской горно-лесистой зоны Чеченской Республики

(по материалам историко-этнографической экспедиции)

Гудименко Д.В. Национализм в современном мире:

типологизация и формы проявления.

Болотин М.С. Историография политического сыска

в Российской Империи 1881-1917 гг.

Борисова $\boldsymbol{E}$. B. Проблемы лесного хозяйства в Крыму

в период установления советской власти в ноябре 1920 года

Мальсагов P.A. Религиозный фактор в общественно-политической жизни современного общества: секуляризация и десекуляризация

Cтоляров A.B. Деятельность ВКП(б) в Среднем Поволжье

в «до колхозный» период: историографический обзор 1920-е - 1930 гг..

Шадышков A.A. Трудовая активность крестьянства Среднего Поволжья в период развитого социализма: историографический взгляд.

ИСТОРИЯ И ТЕОРИЯ ПОЛИТИКИ

Болтенкова Л.Ф. Библия как источник права (часть тринадцатая) 2757

ПОЛИТИЧЕСКИЕ ИНСТИТУТЫ, ПРОЦЕССЫ И ТЕХНОЛОГИИ

Данилов В.А., Данилова Е.В. Трансформация российского

и китайского вектора трансатлантического взаимодействия

на современном этапе

Асси Абед Эль Рахим. Определение понятия имиджа. 2780

\section{ПОЛИТИЧЕСКАЯ РЕГИОНАЛИСТИКА И ЭТНОПОЛИТИКА}

Гаджиев М.M. Основные факторы формирования этнополитики в северокавказском регионе: историческая преемственность и современная реализация. 2786

\section{ТЕОРИЯ И ИСТОРИЯ МЕЖДУНАРОДНЫХ ОТНОШЕНИЙ} И ВНЕШНЕЙ ПОЛИТИКИ

Тушков А.А., Алехина А.П., Животова Д.А. Юго-Восточная Азия в условиях глобального вызова VUKA - World: проблема инклюзивности или инструмент западных технологий? 2798

Сидорова Г.М., Шангараев Р.Н. Особенности развития африканского вектора турецкой внешней политики на современном этапе 2808 Плиев С.М., Кулумбегова Л.Т., Санакоев И.Б., Смолик Н.Г. Мягкая сила как новая система реализации внешнеполитических интересов 
Пикалов Д.В., Пикалова В.С., Макарова О.С., Гончаров А.С.

Отражение актуального фольклора Валахии, Молдавии

и Трансильвании в идейно-образном уровне видеоигры

«Vampire: the Masquerade - Bloodlines»

Петрович-Белкин О.К., Буторов А.С., Буторова О.М.

Российско-армянское сотрудничество в сфере обеспечения

энергетической безопасности на Южном Кавказе (1991-2021 гг.)

Эндрюшко А.A. Ситуативные факторы культурной интеграции

мигрантов в России (на примере граждан Азербайджана)

Aбдусселам Tene. Политические и экономические отношения Турции

с Иракским Курдистаном в контексте ближневосточной

внешнеполитической стратегии Турецкой Республики

Baн Бо. Причины выдвижения инициативы

«Один пояс - Один путь».....

Семенов B.B. Единство в многообразии: Богини

региона Линнань-части древней Юго-Восточной Азии

Чжсан Цзысюань. Модели регулирования

этносоциальной интеграции в Сингапуре

Эгембердиев А.К. Пандемия COVID-19

и уникальный опыт информационной политики в сфере миграции

Хромова А.В. Информационное пространство

как геополитическая категория эпохи глобального мира

СТУДЕНЧЕСКАЯ НАУКА

Ситдиков А.M. Проблемы организации высшей вневойсковой

подготовки в гражданских учебных заведениях СССР в 1930-1938 гг. 2908

КОНФЕРЕНЦИИ

Сыздыкова Ж.С. Фестиваль науки

в Институте стран Азии и Африки МГУ 2918

НАШИ АВТОРЫ 2921

ТРЕБОВАНИЯ К ОФОРМЛЕНИЮ РУКОПИСЕЙ 2928 
аспирант Белорусского государственного университета, Республика Беларусь, г. Минск

\title{
ПРИЧИНЫ ВЫДВИЖЕНИЯ ИНИЦИАТИВЫ «ОДИН ПОЯС - ОДИН ПУТЬ»
}

\begin{abstract}
Издревле в Китае существовал так называемьй Шелковый путь, идея возрождения оного высказал глава КНР в 2013 году. На первом этапе идея базировалась на создании транспортных коридоров между КНР и западной частью Европь, которая является основным потребителем китайской продукции, позднее было выдвинуто предложение по формированию морского пути. Стоит отметить, что отсылка к историческому шелковому пути не является случайной, ныне применяемые маршруты в основе своей повторяют исторические караванные пути. Скептическое отношение к китайской инициативе со стороны многих стран, со временем сменилось на понимание того, что программа в состоянии изменить расклад сил на политической арене. В рамках данной статьи мы изучим причины выдвижения рассматриваемой инициативы.
\end{abstract}

Ключевые слова: Китай, пояс, путь, Россия, взаимодействие.

В 2013 году глава КНР выступил с инициативой «Один пояс - один путь», что касается внутренних причин выдвижения данной инициативы, с началом нынешнего тысячелетия Китай столкнулся с рядом проблем. Западные и восточные области развивались не равномерно, при этом наблюдался избыток производственных мощностей [8. С. 1182-1189]. Что касается неравномерности, она возникла ввиду более интенсивного развития областей приморья. В эти области поступали иностранные инвестиции, были открыты экономические зоны, предприятиям предоставлялись льготы. Таким образом процветало развитие приморских районов, а западные бедные провинции все более отставали, что вызывало волнения среди населения и являлось предметом обеспокоенности властей. Руководство страны предпринимало попытки уравновесить темпы развития обеих областей страны, по средствам субсидирования и улучшения транспортной инфраструктуры отстающих районов, однако данных мер не хватило для существенного изменения дел в стране. При этом инвестирование в развитие внутреннего рынка начатое еще при Ху Цзиньтао в целях минимизации последствий мирового кризиса обострили проблему избытка производственных мощно- 
стей [4. С. 142-151]. В конце первой десятилетки Китаем было вложено много финансов в свою инфраструктуру. Строились дороги, прокладывались железнодорожные пути, возводились жилые и производственные здания. Такие вложения послужили причиной возникновения больших кредитных долгов перед другими государствами, помимо этого возросли производственные мощности строительного назначения. По сей день Китай удерживает первенство по производству строительной продукции. Но, при этом в рамках страны падает спрос на данную продукцию ввиду того, что невозможно постоянно строить в таких объемах, то есть вложения не окупаются [6. С. 279]. При этом импорт данной продукции часто осложнен введением санкций или обвинениями Китая (в первую очередь со стороны США) в искусственном занижении цен.

Правительство КНР стремиться по средствам рассматриваемой инициативы снизить уровень давления избыточных мощностей внутри страны, повысить уровень развития ее западной части. Идея рассматриваемого проекта нацелена на решение проблем неравномерности развития регионов страны по средствам привлечения западной части страны к участию в мировой экономике с последующим выходом на мировой рынок по средством возведения транспортных коридоров. При этом их возведение должно быть реализовано по средствам производственных мощностей и рабочей силы страны. Параллельно с этим в государствах, которые находятся вдоль границ «пояса и пути», запускаются процессы индустриализации и урбанизации, поэтому эти страны вынуждены возводить инфраструктуру применяя технологии Китая и их же специалистов. За время реализации проекта КНР подписал договора с более двух десятков стран, которые расположены на границах маршрутов «пути». Помимо всего прочего КНР таким образом решает свои проблемы в области экологии, перенося производственные мощности в другие страны. К визитным карточкам страны относятся высокоскоростные железнодорожные магистрали, в строительстве и оснащении которых китайцы уже более 10 лет назад ушли от использования заимствованных технологий [7. С. 23-32]. Такие успехи ведут к заключению Китаем многомиллионных контрактов на возведение железных дорог в зарубежных странах, таких как Америка, Великобритания, Европа. Рассматриваемый проект вовлекает в строительство данных дорог страны Европы и Азии, повышая тем самым спрос на саму прокладку дорог и на закупку подвижного состава.

Если сравнивать экспорт Китая и России, то экспорт Китая в области железных дорог сопоставим с экспортом Россией вооружения, а в том случае если будет реализован проект «Сделано в Китае 2025», то объемы превысят мировой экспорт вооружения.

Высокие темпы экономического роста в Китае привели к тому, что Китаю необходимо импортировать углеводороды. Пять лет назад уровень зависимости Китая от данного импорта составлял 65 процентов. Возрастание 
уровня потребления углеводородов в стране до сих пор выше, нежели рост их добычи в рамках страны. Такой уровень зависимости повышает необходимость диверсификации и источников импорта и как следствие каналов поставки углеводородов, так почти весь их объем поступает в страну по проливу, который подконтролен Америке. Поэтому в рамках проектов «Пути» КНР возводит нефтяные и газовые магистрали из России и стран Центральной Азии в обход подконтрольного Америке пролива. Такой подход нацелен на снижение уязвимости процесса поставок и обеспечение необходимого уровня углеводородов по той цене, которая отвечает возможностям страны.

Следует подчеркнуть, что в работах российских и китайских авторов, опубликованных в последние годы, освещается широкий спектр вопросов близких к данной предметной области $[1 ; 2 ; 5 ; 9 ; 10 ; 11]$.

Однако проблему, связанной с китайской инициативой «Один пояс, один путь» нельзя назвать однозначно исчерпанной. В силу многих объективных обстоятельств изучение обозначенной темы продолжает сохранять высокий уровень актуальности.

И так, как упоминалось выше, для Китая данная инициатива нацелена на получение рынков для сбыта продукции. Уже сегодня КНР лоббирует либеральную мировую торговлю с организацией зон свободной торговли. Еще одним стремлением КНР является создание на евразийском континенте пространства экономического и финансового характера, которое было бы завязано на КНР. Помимо этого, прослеживается геополитический фактор, объединение групп стран, которые бы поддерживали Китай или пребывали в зависимости от него.

Что касается Центральной Азии, здесь КНР заметно осторожничает, не имея желания обострять хорошие отношения с РФ. Но стоит обратить внимание на не так давно созданную структуру по борьбе с терроризмом, в которую входит КНР, Пакистан, Афганистан и Таджикистан, а вот связей с ШОС и РФ не наблюдается, что может послужить поводом для размышлений.

Без сомнения, рассматриваемый проект это ключевая часть борьбы КНР за управление новым мировым и финансовым порядком и в то же время глобальный ответ в давнем противостоянии с Америкой. В этом контексте на первый план выходит не только обеспечение безопасности путей доставки углеводородов в КНР, а образование финансовых институтов мирового порядка, которые бы не были зависимы от Америки и западных стран, но пребывали бы под контролем КНР с опорой на финансовую мощь страны.

Обзор причин возникновения проекта КНР демонстрирует трудности сопряжения проекта Китая и российского проекта ЕАЭС. Так проект РФ нацелен на создание единого экономического пространства РФ, РБ, Казахстана, Киргизии и Армении для выстраивания сотрудничества в сфере политики и экономики, которое бы было завязано на РФ и включало в себя формирование единой таможенной зоны для защиты рынка данных стран от проникно- 
вения товаров других стран. Такой подход расходится с целями КНР выстроить по средствам ОПОП расширение рынков сбыта китайской продукции.

В то же время Китай оказывает серьезное давление на своих соседей и партнеров, желающих принять участие в проекте «Пояс и путь» - формирование той или иной формы ЗСТ с Китаем (на двусторонней или коллективной основе) фактически является одним из условий китайского участия и инвестиций.

Поскольку Казахстан, который первоначально предложил проект ОППО, а затем Беларусь, наряду с другими странами, активно участвующими в китайском проекте, соревнуются за право представить себя в качестве «главного хаба» для Китая или главного партнера в продвижении проекта ОППО, будущее Евразийского экономического союза в его предполагаемой форме представляется, мягко говоря, мрачным.

Обратите внимание, что Казахстан и Беларусь - далеко не единственные страны, стремящиеся стать одними из главных или основных бенефициаров китайского проекта: в очереди стоят самые разные страны, от крошечной Латвии до довольно респектабельной Великобритании, не говоря уже об Украине, Греции, Венгрии и других. Привлекательность китайского проекта для элит этих стран заключается в возможности получения кредитов, привлечения китайских инвестиций, развития инфраструктуры и так далее. Неслучайно Китай подчеркивает преимущества проекта для всех странучастниц и позиционирует его в рамках концепции «общей судьбы» всего человечества. Утверждение о том, что все страны могут выиграть от присоединения к Китаю как к «экономической державе», постоянно повторяется в заявлениях китайских лидеров на международной арене [3. С. 50-56].

Однако не следует забывать, что проект также является частью так называемой «китайской мечты», которая понимается, прежде всего, как идея «великого омоложения великой китайской нации». Хотя все страны приглашаются присоединиться к «китайской мечте» (в рамках «общей судьбы»), она в первую очередь заботится о национальных интересах Китая, а не об «обогащении» соседних стран.

\section{БИБЛИОГРАФИЧЕСКИЙ СПИСОК:}

1. Ван Цзясюй. Китайская мечта как цель политической модернизации // Вопросы политологии. 2021. Т. 11. № 4 (68).

2. Ван Цзиньхуэй. Внешняя политика КНР на Дальнем Востоке: проблемы и перспективы // Вопросы политологии. 2021. Т. 11. № 2 (66).

3. Дабылтаева Н.Е., Юань М.M. Ресурсная политика во взаимодействии со Стратегией Экономического пояса Шелкового пути // Проблемы агрорынка. 2021. № 1 .

4. Карпович О., Смагина Л. Реализация инициативы «Один пояс, один путь» на постсоветском пространстве: плюсы и минусы для России // Дипломатическая служба. 2021. № 2. 
5. Красавин Д.В., Попов Д.Г. Аналитические центры в постсоветских странах Центральной Азии - особенности восприятия векторов внешней политики (на примере проектов ЕАЭС и «Один пояс - один путь») // Вопросы политологии. 2021. Т. 11. № 6 (70).

6. Погодин С.Н., Цзинчэн Л. История создания китайского проекта «Один пояс, один путь» // Актуальные проблемы мировой политики. 2021.

7. Сазонов С.Л. и др. «Один пояс и один путь» как важнейший проект стимулирования экономического развития КНР // Вестник транспорта. 2021. № 2.

8. Сыздыкова Ж.С. Мегапроект Китая «Один пояс, один путь»: внутренние и внешние вызовы // Вопросы политологии. 2021. Т. 11. № 4.

9. Тушков А.А., Данилова А.И. Этнополитический конфликтный потенциал современного Китая // Вопросы политологии. 2021. Т. 11. № 3 (67).

10. Чжан Лумэн. Изменения в мировом порядке в постэпидемическую эпоху и ролевое позиционирование Китая // Евразийский Союз: вопросы международных отношений. 2021. Т. 10. № 1 (35).

11. Чу Лин, Хань Хаолэй. Динамика китайско-российского энергетического сотрудничества в контексте двусторонних политических отношений // Вопросы политологии. 2021. Т. 11. № 4 (68).

WANG BO

Graduate student, Belarusian State University, Minsk, Republic of Belarus

\section{REASONS FOR THE ONE BELT, ONE ROAD INITIATIVE}

Since ancient times in China there was the so-called Silk Road, the idea of its revival was expressed by the head of China in 2013. At the first stage, the idea was based on the creation of transport corridors between China and the western part of Europe, which is the main consumer of Chinese products, later the proposal to form a sea route was put forward. It is worth noting that the reference to the historical silk road is not accidental, the currently used routes basically repeat the historical caravan routes. Skepticism about the Chinese initiative on the part of many countries, over time, has been replaced by the understanding that the program is able to change the balance of power in the political and political arena. In this article we will examine the reasons for the initiative under consideration.

Key words: China, Belt and Road, Russia, interaction. 